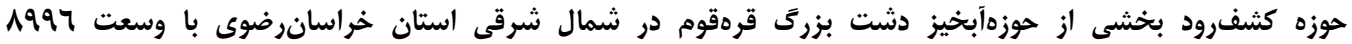

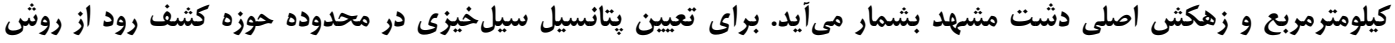
اصلاح شده، درمحيط GCS

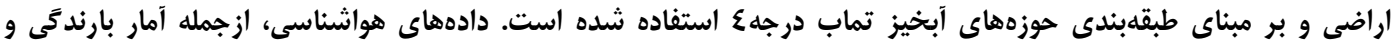

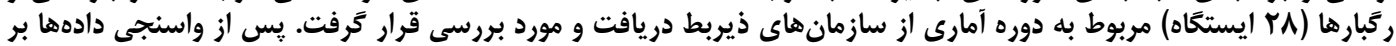

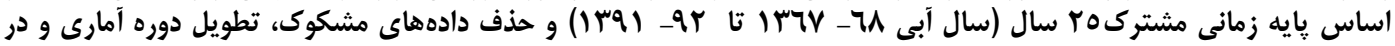

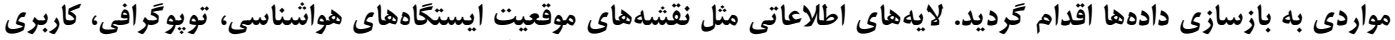

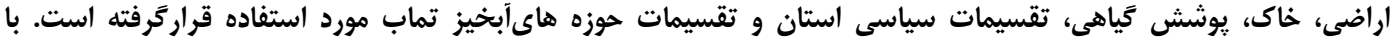

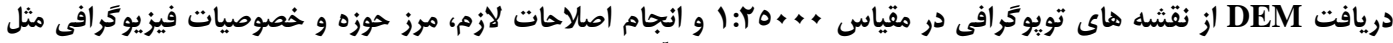

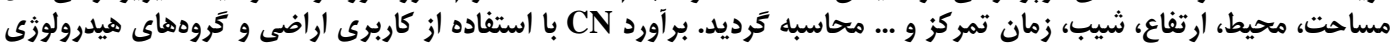

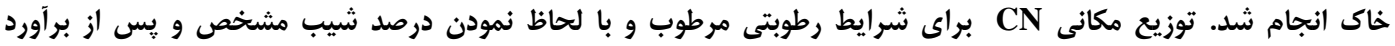

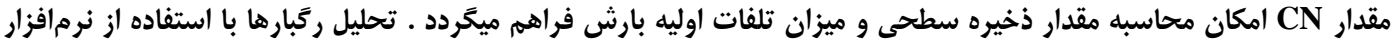
SMADA

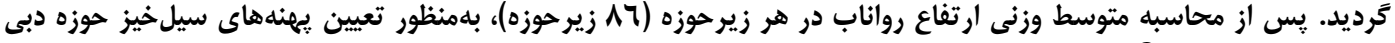

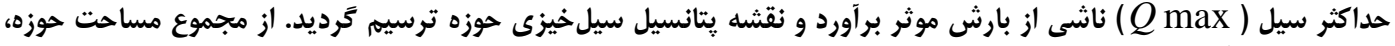

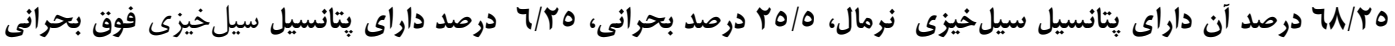

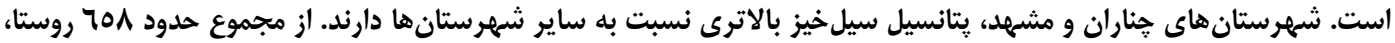

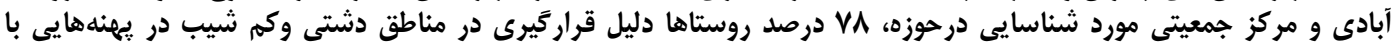

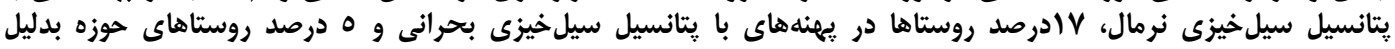

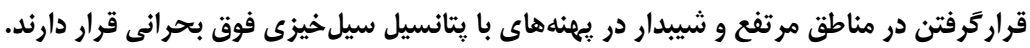

وازههاى كليدى: پتانسيل سيلخيزى، حوزهآبخيز، سيلاب، حوزهشفرود، روش SCS

داخل حوزهآبخيز با مشكل مواجه مىشود. جه بسا در يارهاى

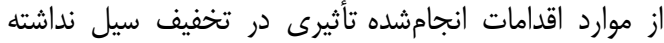

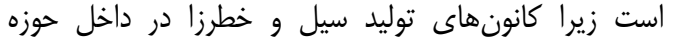
مشخص نشده است.

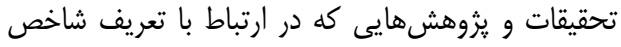

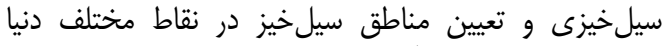

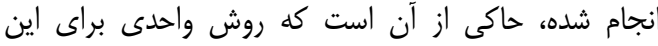

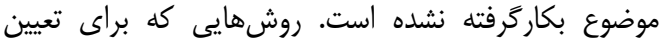

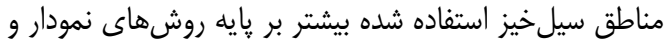

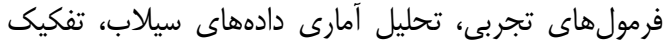

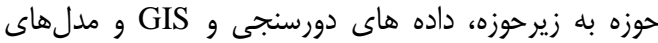

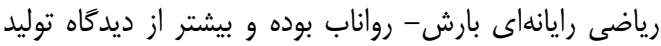

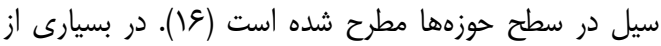

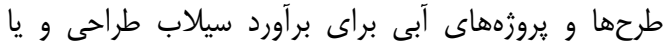

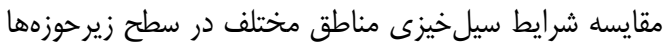

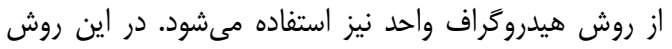

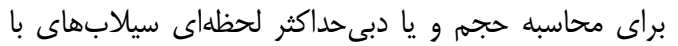

مقدمه

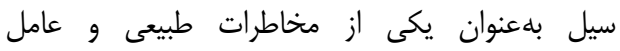

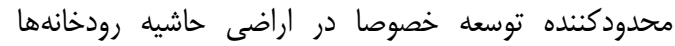

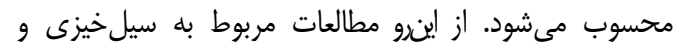

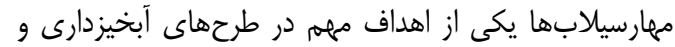

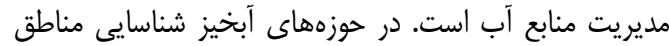

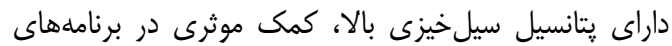

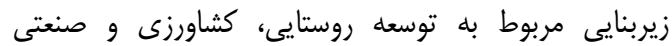

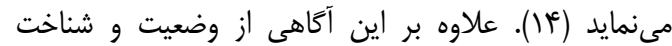

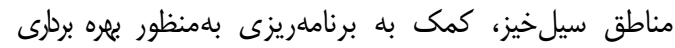

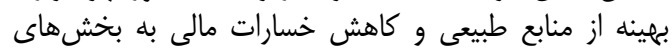

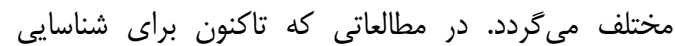

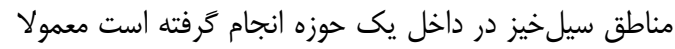

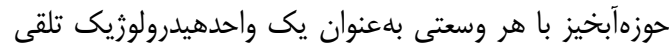

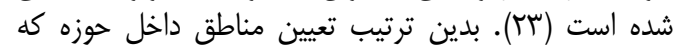

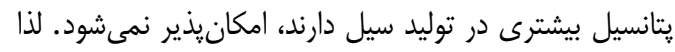

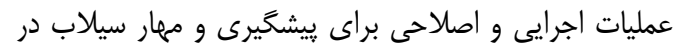


يُوهشنامه مديريت حوزه آبخيز سال نهم/ شماره IV بهار و تابستان Vوسا .

مقايسات زوجى، با روش فرآيند تحليل سلسله مراتبى (AHP)

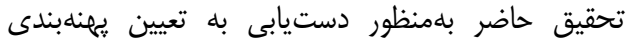

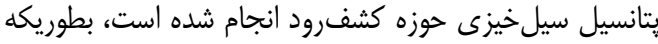

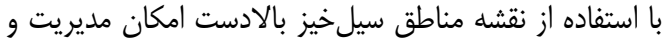

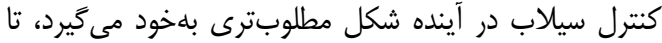
از خسارت سيل به ساختمانهاى مسكونى و اراضى زئى زراعى،

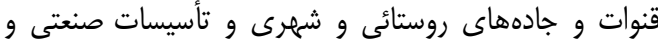

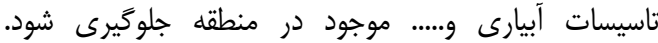
نقشههاى خطريذيرى سيلاب ميتوانند ابزار مناسبى براى

برنامهريزىهاى شهرى در آينده باشند (9).

$$
\text { مواد و روش ها موردي }
$$

بررسى موقعيت كلى منطقه مورد مود مطالعه

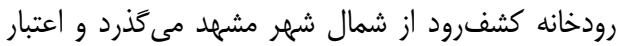

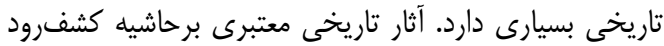

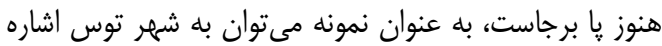

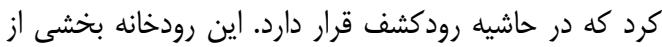

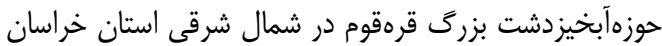

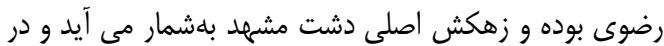

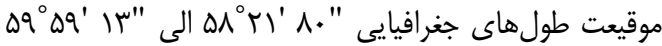

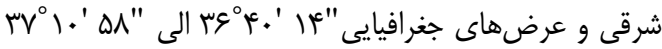

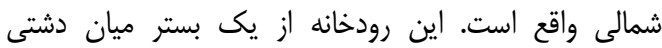

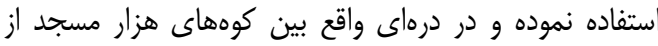

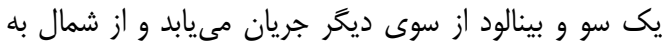

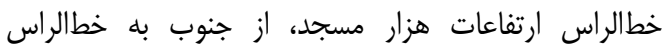

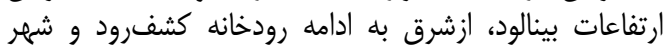

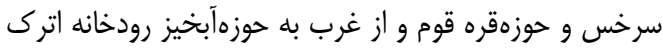

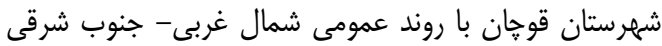
محدود مى شود (شكل ( ) ). وسعت كل حوزه حدود

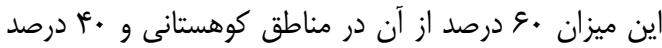

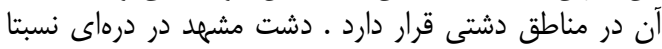

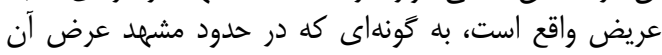

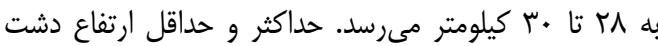

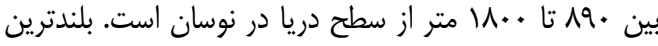

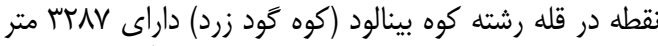

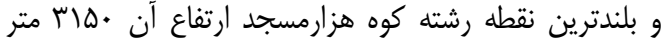

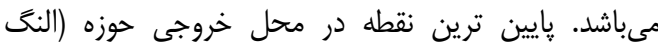

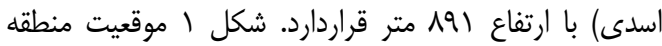
مطالعاتى را نشان مى ارتفاع إند متر
دوره بر گشت مختلف در هر زيرحوزه، با استفاده از روش SCS محاسبه مىشود.

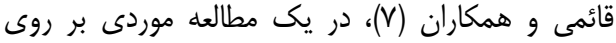

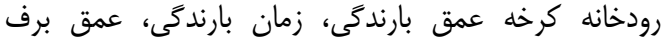

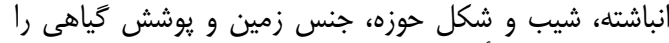
بهنوان عوامل تأثير كذار بر سيلاب ارائه دادند.

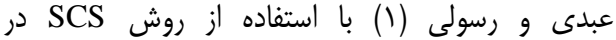

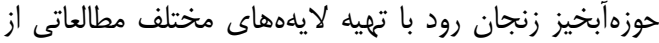

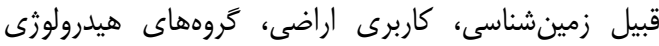

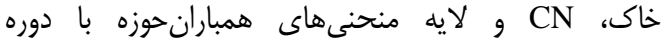

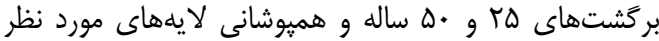

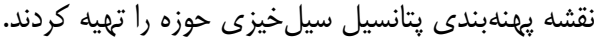

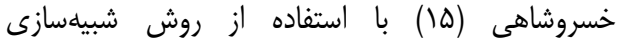

هيدرولوزيكى در تبديل رابطه بارش رواناب (Simulation)

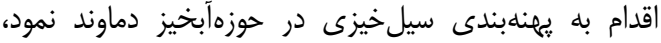

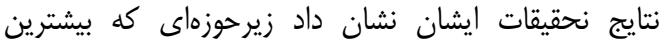

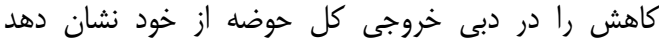

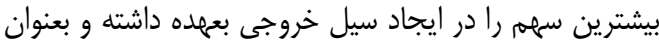

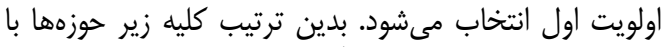

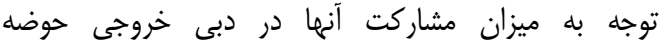

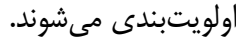

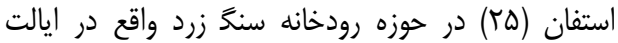

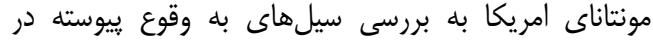

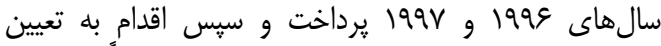
يمينهایىسيل

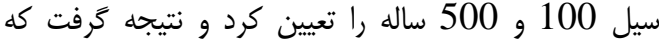

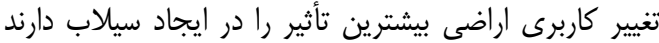

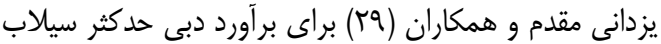

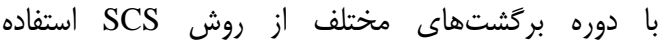
كردند،نتايج تحقيقات وى دو نشان داد دادكه تغيير كاربرى، شيب

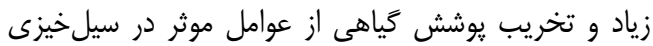
حوزههاى كاشان است.

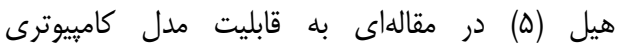

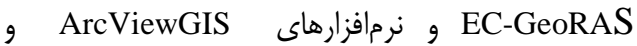
HEC-RAS

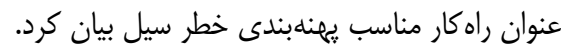

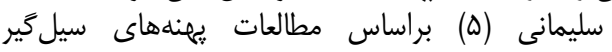

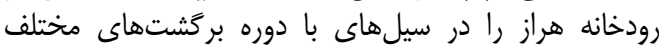

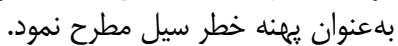

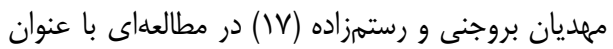

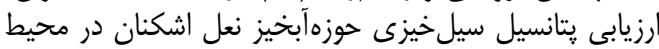
GIS

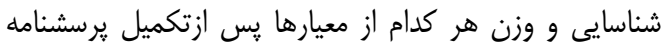



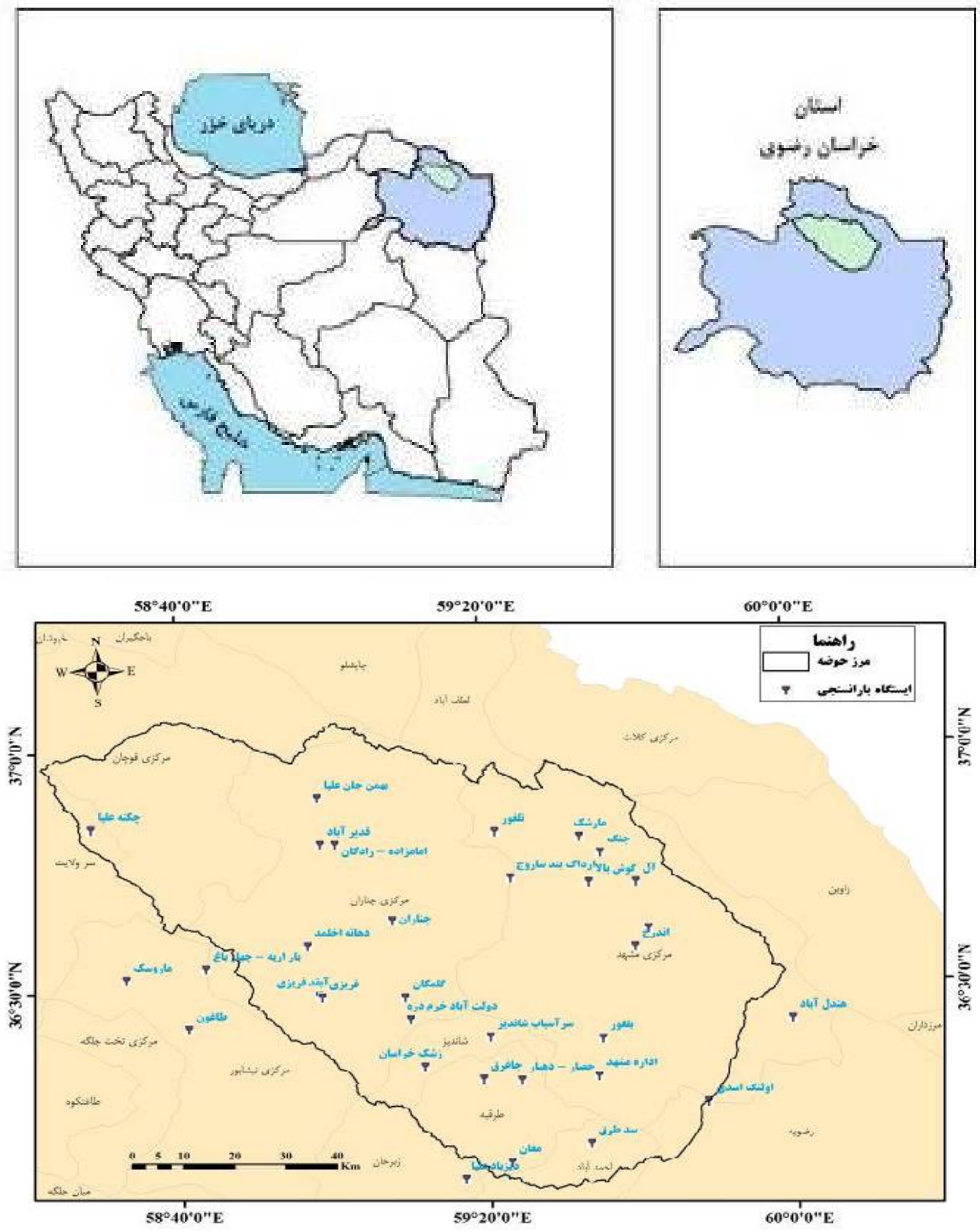

شكل ا- - نمايى از نقشه موقعيت يراكنش ايستخاههاي هواشناسى و موقعت كلى حوزه كشفرود نسبت به سطح كشور و استان خراسان رضوى Figure 1. Map of the location the distribution of weather stations and the position of Kashafrud watershed relative to the country level and Khorasan Razavi province

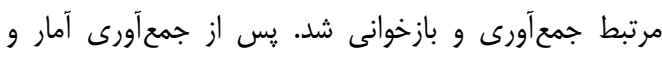

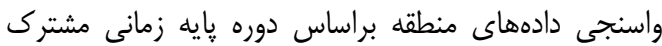

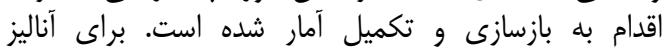

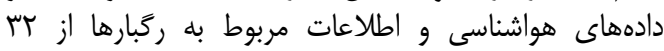

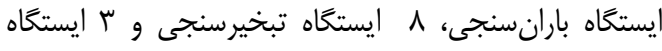

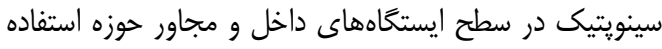

شده است (r.).
جمع آورى اطلاعات و دادههاى مورد نياز

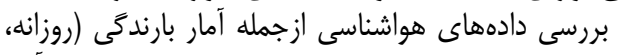

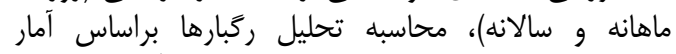

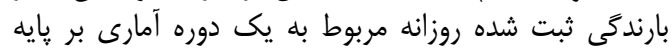

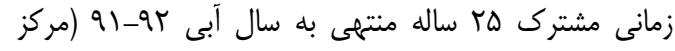

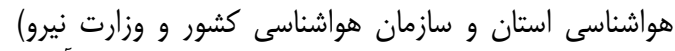

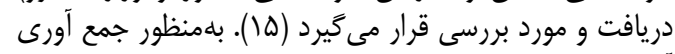

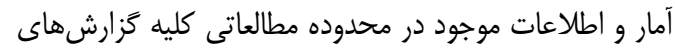




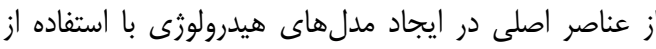

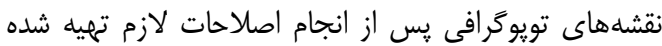

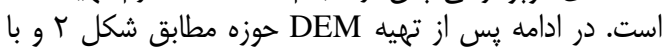

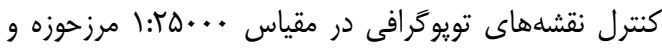

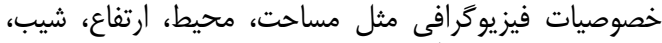

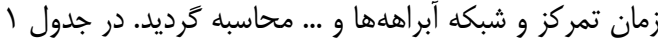

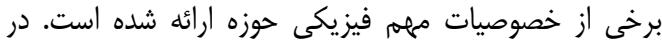

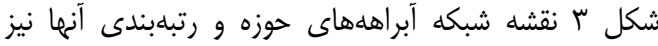

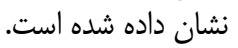

لايههاى اطلاعاتى متعددى در اين تحقيق استفاده شده

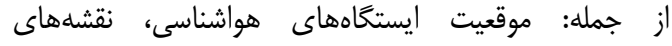

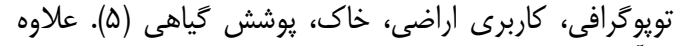

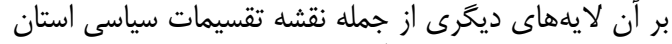

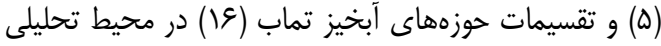
GIS

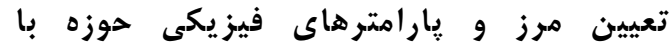
استفاده از مدل مرز (DEM) دراين تحقيق مدل رقومى ارتفاع (DEM) بهنه ادعنوان يكى جدول 1- هارامترهاى فيزيكى استخراج شده در حوزه كشفرود

Table 1. Physical parameters extrated of Kashafrud watershed

\begin{tabular}{|c|c|c|c|c|c|c|c|c|c|c|c|c|}
\hline متوسيب & \multicolumn{3}{|c|}{ ارتفاع حوزه(متر ) } & \multirow{2}{*}{$\begin{array}{c}\text { كشيدگى نسبت } \\
\text { (Re) }\end{array}$} & \multirow{2}{*}{$\begin{array}{l}\text { ضراويليوس } \\
\text { (c) }\end{array}$} & \multicolumn{3}{|c|}{ زمان تمركز Tc (ساعت) } & \multirow{2}{*}{ 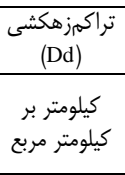 } & \multirow{2}{*}{ 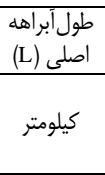 } & \multirow{2}{*}{$\begin{array}{c}\text { كيلومتر } \\
\text { (P) } \\
\end{array}$} & \multirow{2}{*}{$\begin{array}{c}\text { كساحتوتر } \\
\text { (A) } \\
\text { مربعر }\end{array}$} \\
\hline درصد & متوسط & حداقل & حداكثر & & & جياندوت & كرييج & برانس بان & & & & \\
\hline $1 \% / \Delta$. & IQHY & 191 & TYAV & $\cdot / V$ & $T / \mathcal{E V}$ & rI/.q & $I V / \Delta$. & $r V / N E$ & $r / 9$. & $199 / 9$ & 191 & 1998 \\
\hline
\end{tabular}

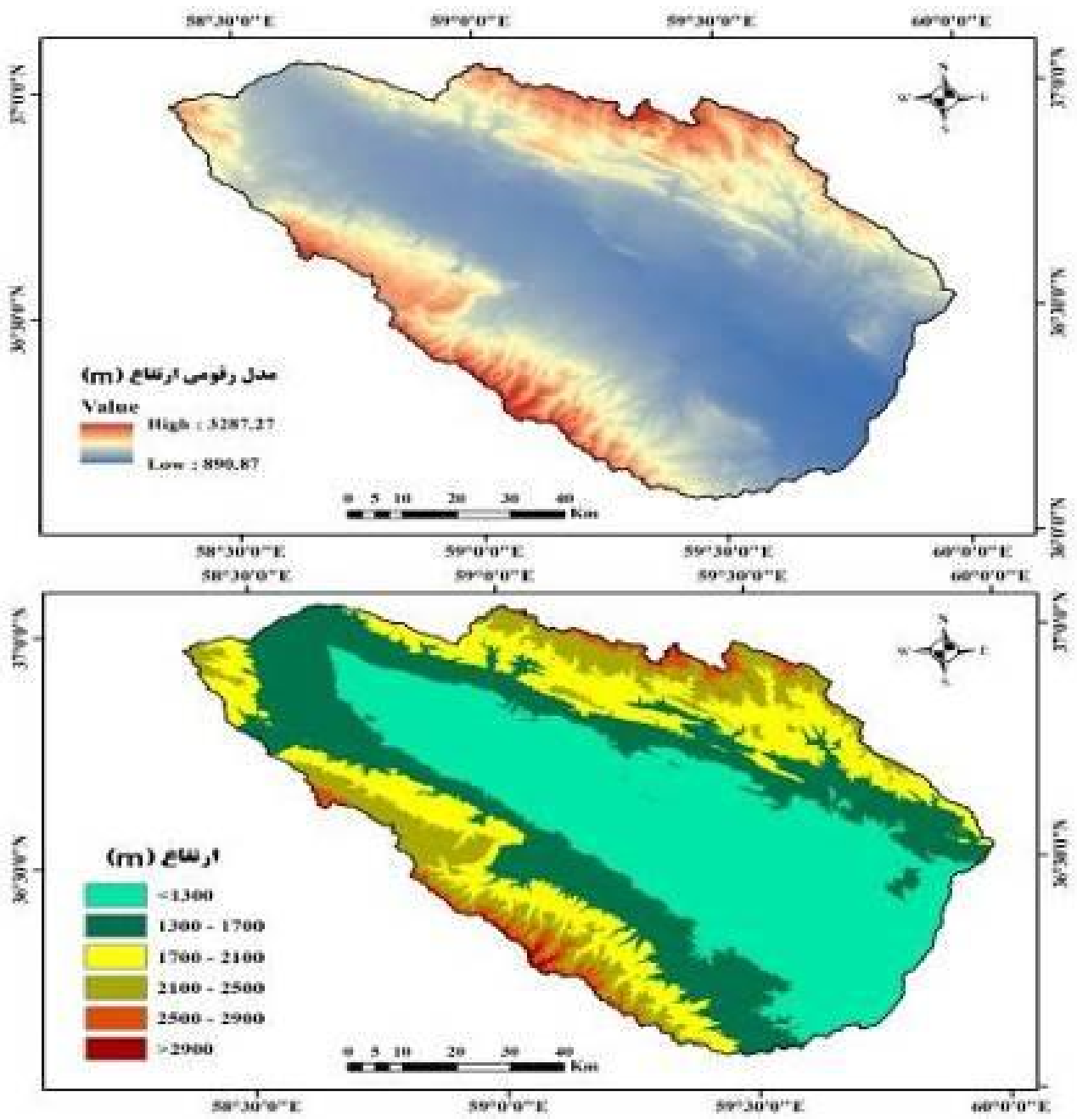

شكل r- نقشههاى مدل رقومى ارتفاع (DEM) حوزه

Figure 2. Maps of Digital Elevation Model (DEM the watershed 


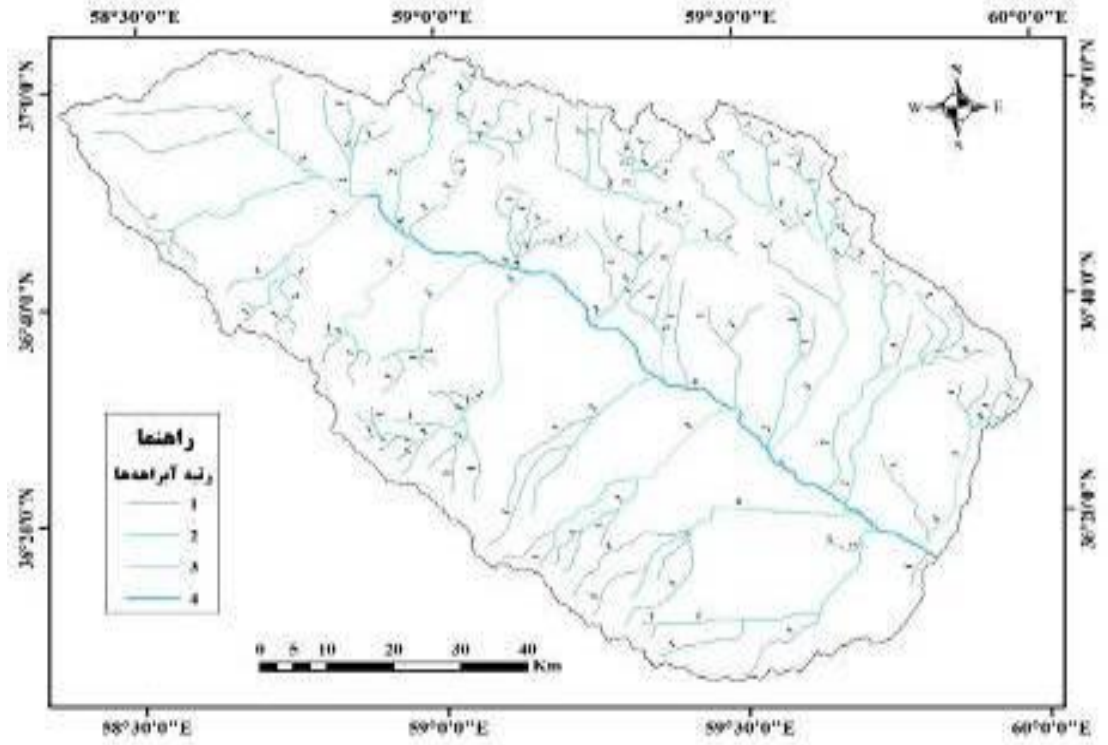

شكل س- نقشه شبكه آبراهdهاى حوزه كشفرود و رتبلهبندى آنها

Figure 3. Map of the ranked hydrographical network of Kashafrud watershed

انجام شود، منطقه مورد مطالعه درحوزهقره قوم باكد 9 و و

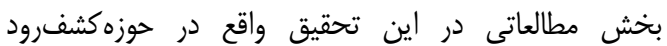

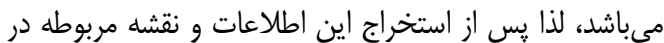

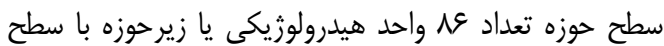

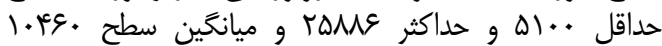
هكتار تفكيك و در شكل ع نشان داده شده است.
از آنجا كه معمولا وضعيت سيلخيزى حوزه بايستى زئى

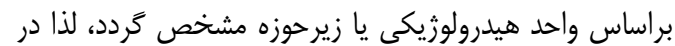

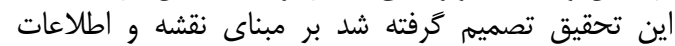

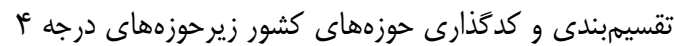

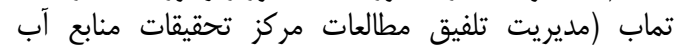
كشور) (الr) برشهاى لازم مربوط به مرزحوزه و زيرحوزهنات

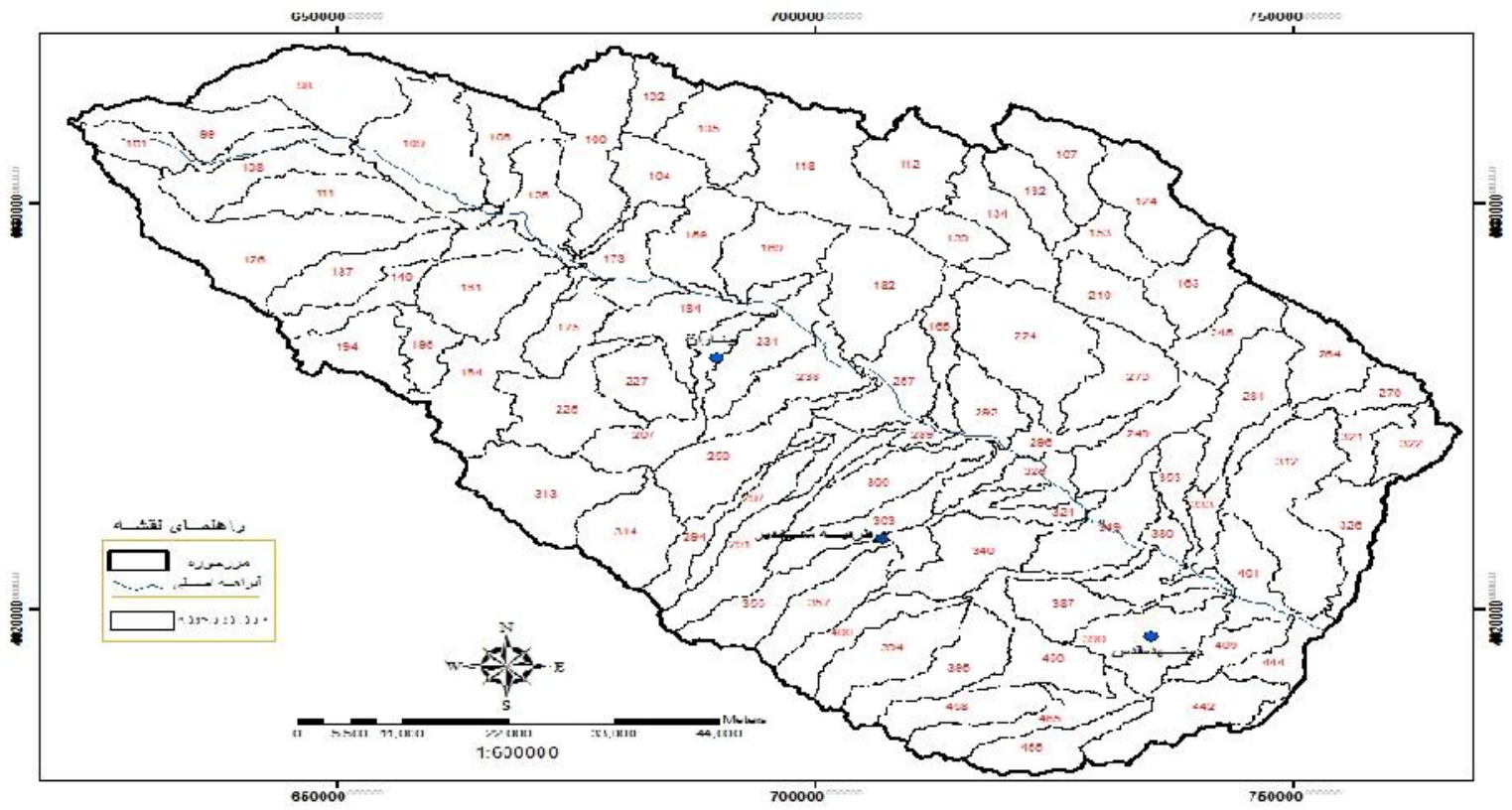

شكل ع- نقشه زيرحوزهاى استخراج شده از در محدوده حوزه كشفرود بر اساس نقشه تقسيمبندى تماب درجه f Figure 4. Map of the sub- watershed extracted from the Kashafrud watershed based on TAMAB Map 


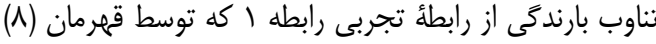

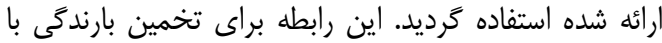

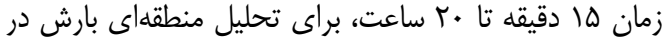

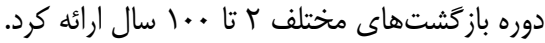

$P_{T}^{t}=(0.4055+0.2636 \ln (T-0.4400))$ $\left(-0.2420+1.2452 t^{0.2674}\right) p_{10}^{60}$

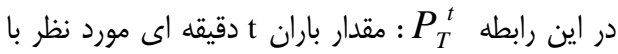

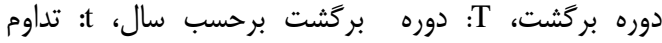

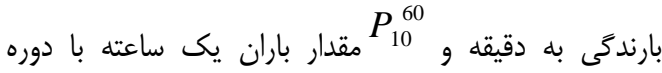
برگشت • إل سال مىباشد.
تحليل رَّبارها در محدوده هطالعاتى

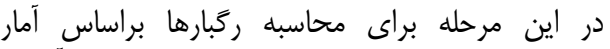

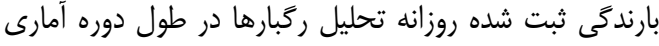

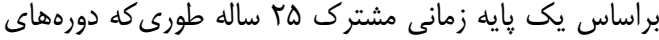

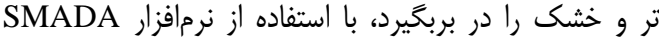

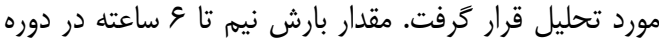

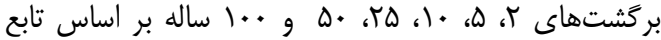

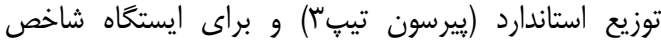

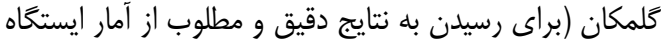

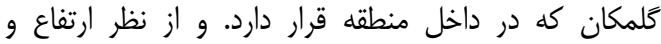

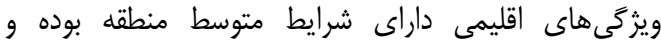

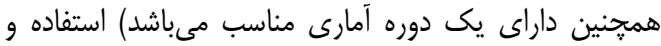

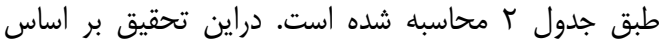

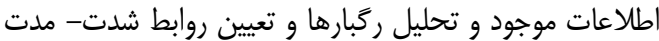

جدول r- مقادير شدت بارندكى حوزه براساس ايستخاه شاخص كلمكان" در زمان هاى مورد نظر (ميلىمتر بر ساعت) Table 2. Rrainfall intensity of the watershed based on Golmakan* station index at the desired time (m/ h)

\begin{tabular}{|c|c|c|c|c|c|c|}
\hline دوره بر گشت (سال) زمان (دقيقه) & r & $\Delta$ & 1. & $r \Delta$ & ఎ. & $1 .$. \\
\hline$r$. & $90 / 14$ & $99 / \Delta 9$ & ה & $|Q| / \cdot \Delta$ & $I V T / R \Delta$ & $19 T / T V$ \\
\hline 9. & $\kappa r / \cdot V$ & SD/AT & $1 . / 94$ & $99 / \mathrm{M}$ & $11 \% / 9$. & $1 T V / V q$ \\
\hline $1 T$. & $r N / V$. & $\uparrow \Psi / A V$ & $\Delta r / q r$ & $99 / \Delta \Delta$ & $v \Delta / \Lambda q$ & $\Lambda \Delta / / \Delta$ \\
\hline 14. & $r r / v$. & $\mu \varphi / q q$ & $F Y / \& D$ & $\Delta T / G T^{H}$ & $9.1 . r$ & sV/r山 \\
\hline rF. & $19 / T F$ & $r q / 4)$ & $r q / \| f$ & $|\psi| c|q|$ & $\Delta \cdot / A V$ & $\Delta V / \cdot \wedge$ \\
\hline . & $\mid \Delta / r q$ & Tr/Tr & $T N / 9 V$ & $\Gamma \Delta /{ }^{\prime}$ & $\tau \cdot / \pi \Delta$ & $r \Delta / T V$ \\
\hline
\end{tabular}

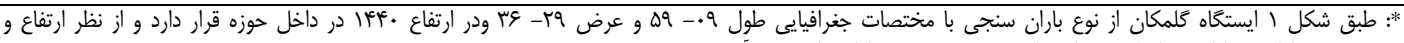

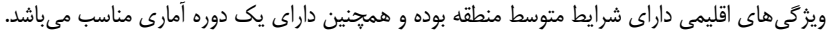

براساس رابطه فوق و ارتباط بين ذخيره در دو حالت فوق $S_{0.05}=1.33 \times\left(S_{0.02}\right)^{1.15} \quad$ رابطه (f)

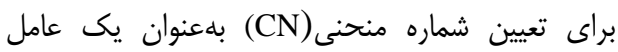

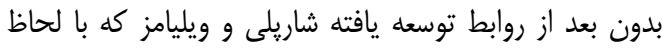

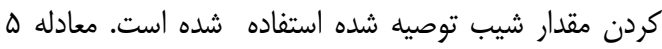

رابطه بيشنهادى شاريلى و ويليامز را بيان مى كند (IV). (ه) (ه) رابطه

$$
\begin{aligned}
& C N_{2 a}=\frac{1}{3}\left(C N_{3}-C N_{2}\right)\left(1-2 e^{-13.86 a}\right)+C N_{2}
\end{aligned}
$$

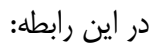

$$
\begin{aligned}
& \text { } \\
& \text { : شماره منحنى در شرايط رطوبتى مرطوب : }
\end{aligned}
$$

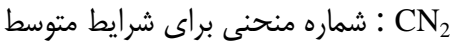

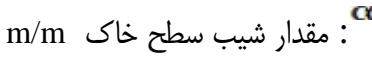

$$
\begin{aligned}
& \text { مجاسبه عمق بارش موثر باري }
\end{aligned}
$$

طبق روش SCS عمق بارش موش موثر بر بر مبر مبناى تحليل

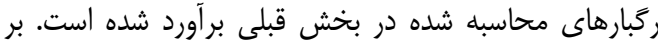

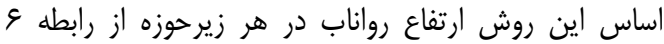
$R=\frac{(P-0.2 S)^{2}}{2(P-.0 .8 S)}$
محاسبه ذخيره سطحى و نقشه شماره منحنى (CN)

طبق روش SCS مقدار ذخيره سطحى يا مقدار نكمهاشت

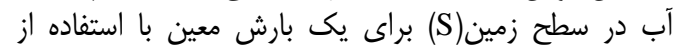

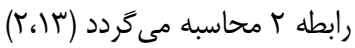

انتخاب شماره منحنى يا (Curve Number)CN

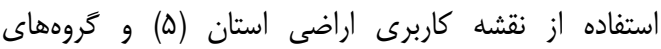

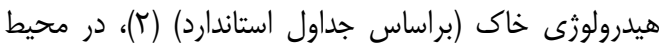

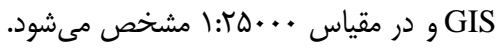

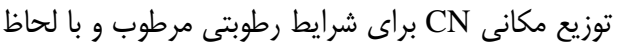

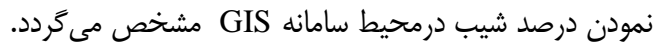

$$
S=\frac{25400}{C N}-254
$$

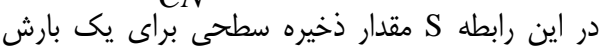

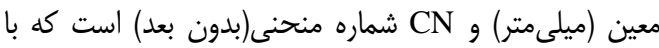

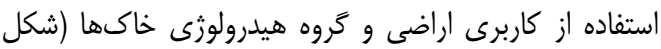

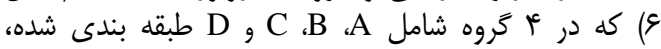

$$
\text { مشخص مىشود. }
$$

مقدار تلفات اوليه بارش (La ) مa بر اساس نظر هوكينز

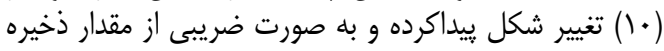
سطحى محاسبه شده طبق رابطه بَ ارائه شدهاست. $L a=0.05 \times S$

رابطه (ॅ) 
در اين رابطه A: مساحت به كيلومتر مربع، R: ارتفاع روان

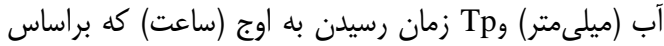
زمان تمركز قابل محاسبه است.

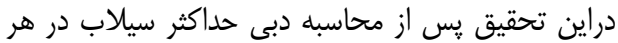

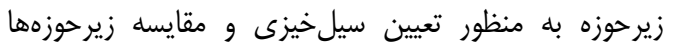
مقادير طبقهبندى شده و بصورت كيفى و در ها ه كلاس شامل

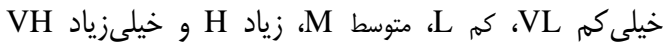

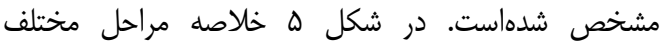
محاسبه دبى حداكثر سيلاب بصورت شماتيك نشان داده
در اين رابطه R: ارتفاع روان آب (ميلىمتر)، P:ارتفاع بارندگى

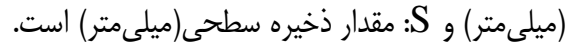

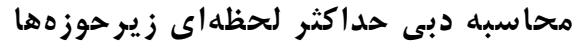

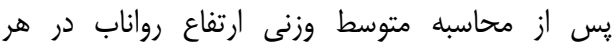

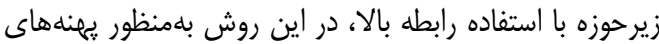

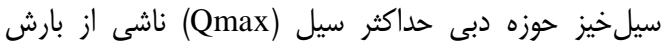

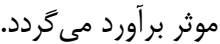
براى اين منظور با استفاده از رابطه V حبر دبى حداكثر

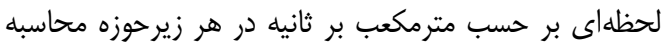

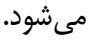
$Q \max =\frac{2.083 \times A \times R}{T p}$ (V) رابطه

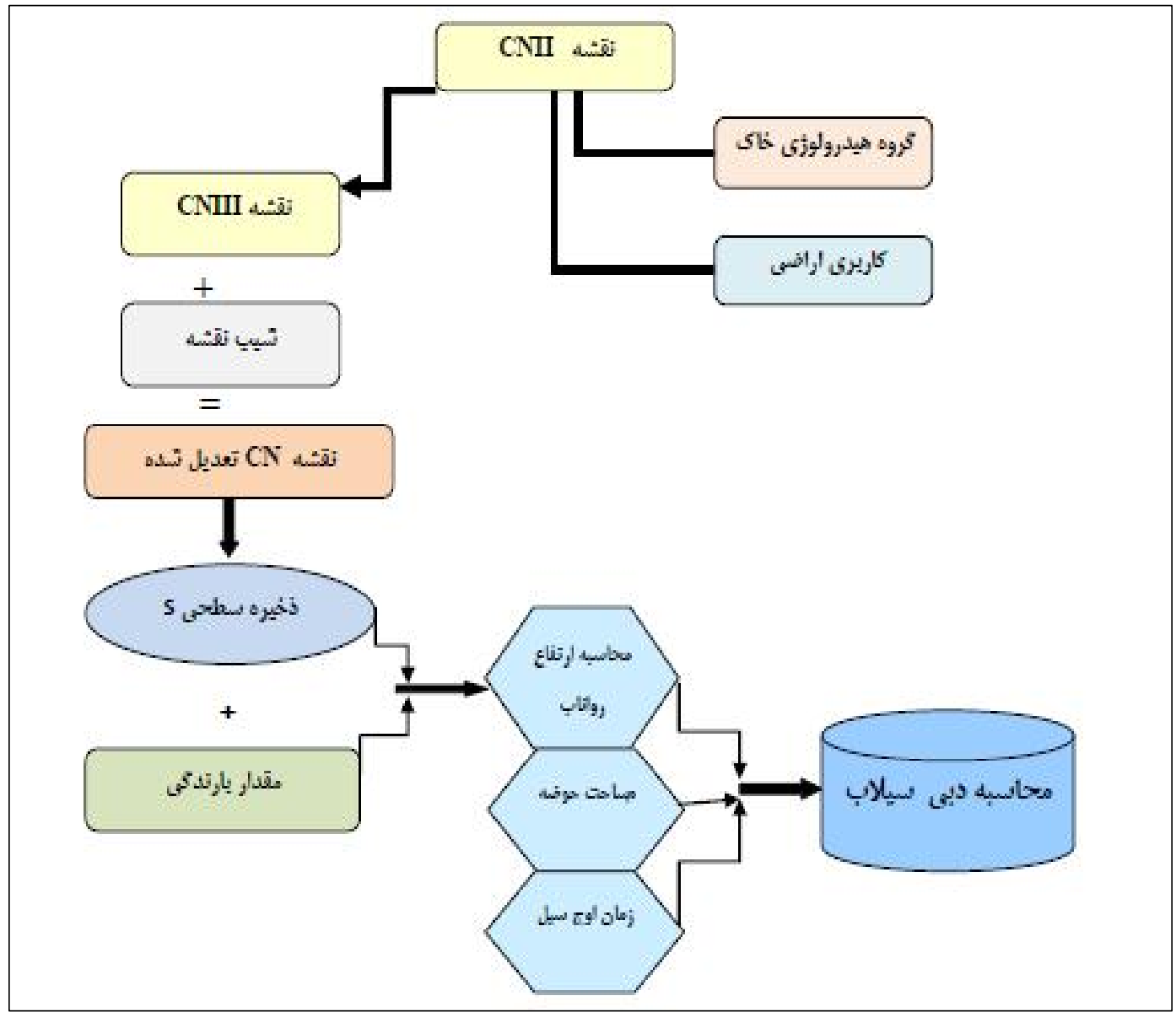

شكل ه-- مراحل محاسبه دبى سيلاب حوزه براساس روش SCS

Figure 5. Flood discharge calculation steps of the watershed based on SCS method

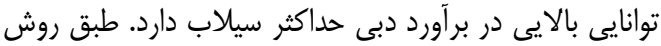

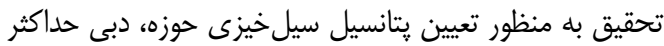

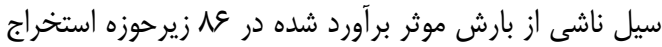

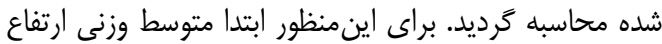

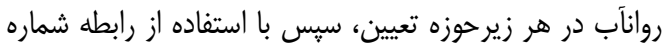
V دبى حداكثر لحظهاى زيرحوزهها محاسبه شد.

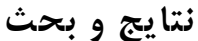

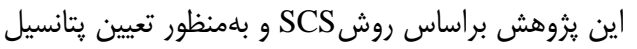

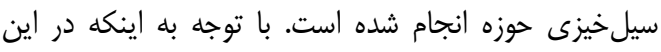

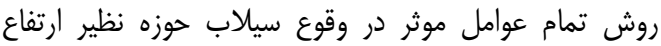

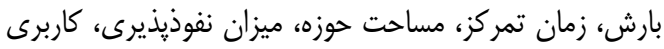
اراضى و ضريب توليد رواناب لحاظ مى ميزن نُود لذا اين مدل كاري 
يراساس تلفيق نقشه CN حوزه (شكل V V) در محيط

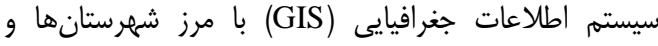

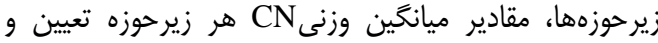

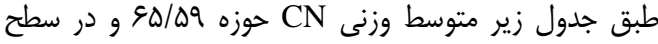

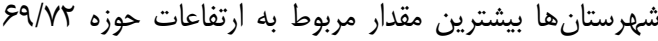

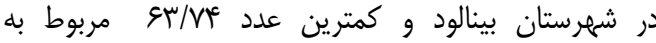
شهرستان مشهر محاسبا شده است.

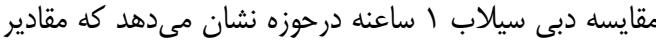

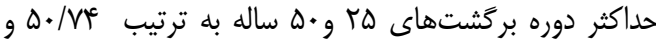

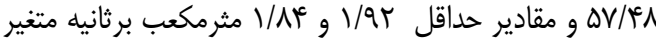

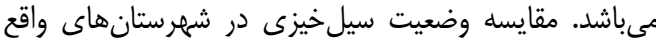

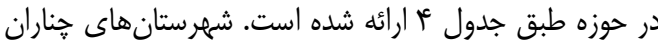

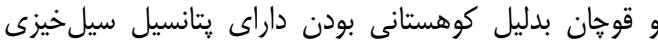
نسبتا بالاترى نسبت به ساير شهرستان ها دارند.
با استفاده از لايه مرز شهرستانها و انطباق آن با لايه

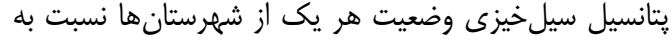

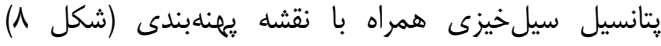

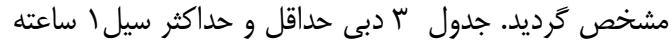

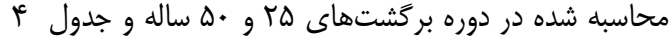

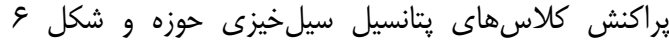

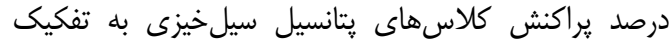

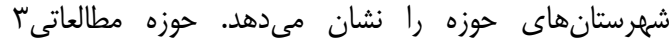

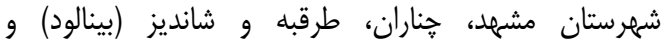

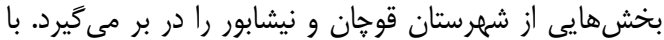

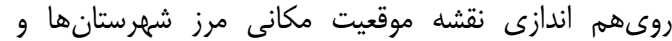

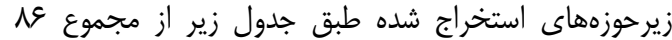

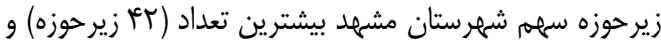

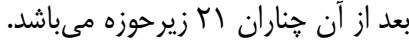

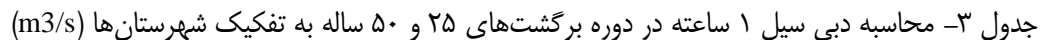
Table 3. Calculation of 1 hour flood discharge in the period of 25 and 50 years extracted by cities (m3/s)

\begin{tabular}{|c|c|c|c|c|c|c|}
\hline \multirow{2}{*}{ شهرستان } & \multirow{2}{*}{ زيرحوزه } & \multirow{2}{*}{ CN متوسط CN } & \multicolumn{2}{|c|}{ دبى ا ساعنه •D ساله } & \multicolumn{2}{|c|}{ دبى اساعته } \\
\hline & & & حداكثر & حداقل & حداكثر & حداقل \\
\hline بينالود & ir & gq/Vr & $r . / 9 \Lambda$ & $1 / F \Delta$ & $r V / q$. & $1 / A T$ \\
\hline جناران & rI & $99 / 1 f$ & $9 . / 97$ & $1 / 19$ & $V q / T g$ & $1 / V \pi$ \\
\hline قوخان & $\wedge$ & SF/AT & TI/AT & $\Delta / \&$. & TN/THE & $r / v$. \\
\hline مشهد & et & sr/VF & $\mathrm{FV} / .9$ & I/Ar & $F+/ 1 \Lambda$ & I/At \\
\hline ن نيشابور & r & SN/TA & $\mid F / v i$ &.$/ 91$ & ( & • / \\
\hline حوزه & $1 \varepsilon$ & $90 / 09$ & $\Delta V / \uparrow \wedge$ & $1 / \lambda i^{2}$ & $\Delta \cdot / V f^{c}$ & $1 / 9 r$ \\
\hline
\end{tabular}

جدول fأ- يراكنش شدت يتانسيل سيلخيزى حوزه به تفكيك شهرستانها (هكتار) Table 4. Dispersion of the intensity of the flooding the watershed extracted by cities (hectares)

\begin{tabular}{|c|c|c|c|c|c|}
\hline \multirow[t]{2}{*}{ شهرستان } & \multicolumn{2}{|c|}{ نرمال } & \multirow{2}{*}{ سيل خيزى متوسط M بحرانى } & \multicolumn{2}{|c|}{ فوق بحرانى } \\
\hline & سيل خيزى خيلى كم VL & سيل خيزى كم L & & سيل خيزى زياد H & سيل خيزى خيلى زياد VH \\
\hline بينالود & $V \cdot \Delta F \cdot / V I$ & FVQDI/rA & .1 .9 & - & - \\
\hline جیاران & ו ו IVGKF & IMFAFN/D. & 1. $r V Y F / I r$ & TVTNE/S. & $V \cdot r / \propto \mu$ \\
\hline قُ حُان & $\mid 109 \% / \Lambda 1$ & 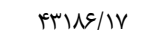 & $f+\wedge \Delta I / \wedge \Delta$ & MAET/K. & - \\
\hline مشهد & 1/9r & $\mid V T A \Delta T / \cdot A$ & $9991 N / 09$ & & - \\
\hline نيشابور & - & $r M \mu / \Delta)$ & $|M| M F / \lambda S$ & $m 119 / \mu$. & - \\
\hline جمع حوزه & TINAFE/ND & F. MFYI/DF & rYqTVN/VA & $F 9 Y 4 N / .9$ & $V \cdot r \mid / F r$ \\
\hline درصديراكنش & rT/QT & $F F / N$ & $r \Delta / \Delta$. & $\Delta / \& V$ &.$/ \mathrm{VA}$ \\
\hline
\end{tabular}




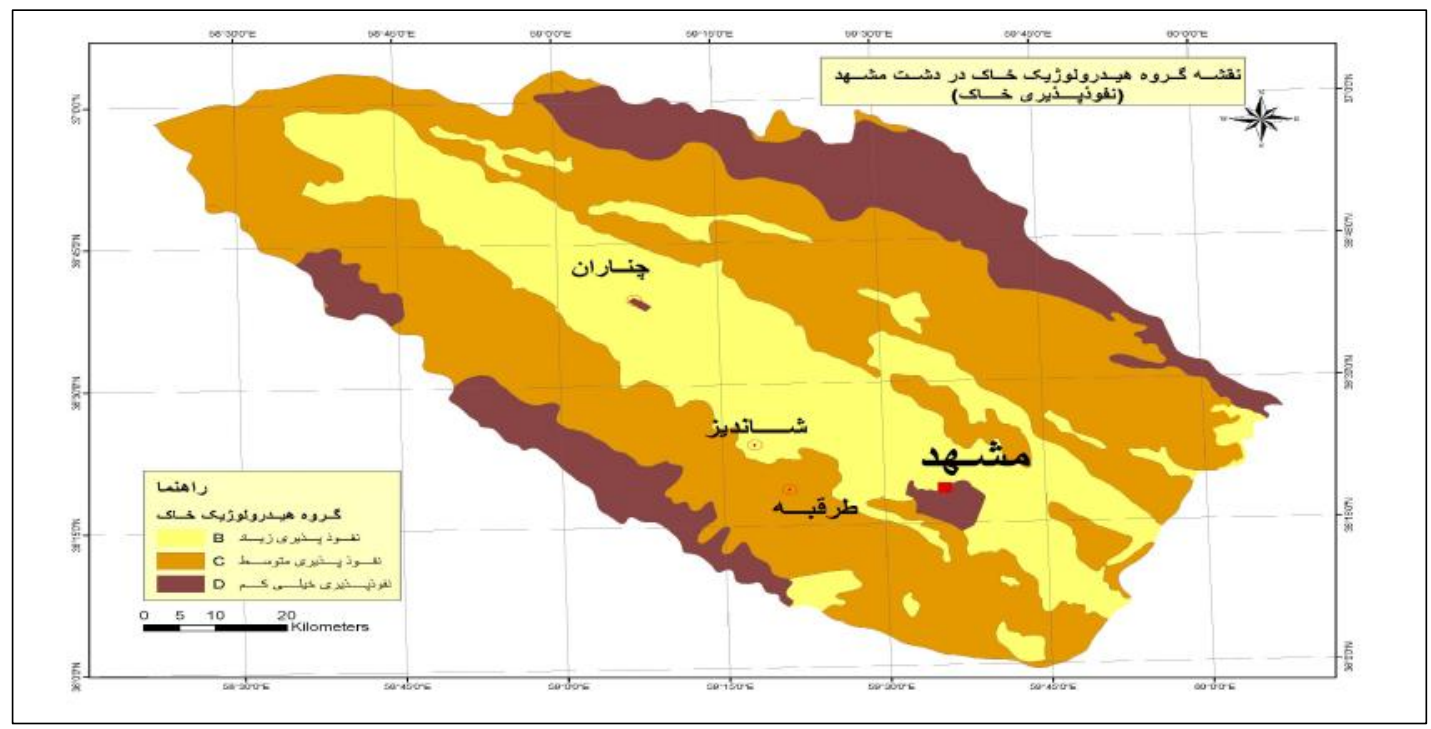

شكل צ- نقشه گروهاى هيدرولوزى خاك حوزه

Figure 6. Map of Soil Hydrology Groups

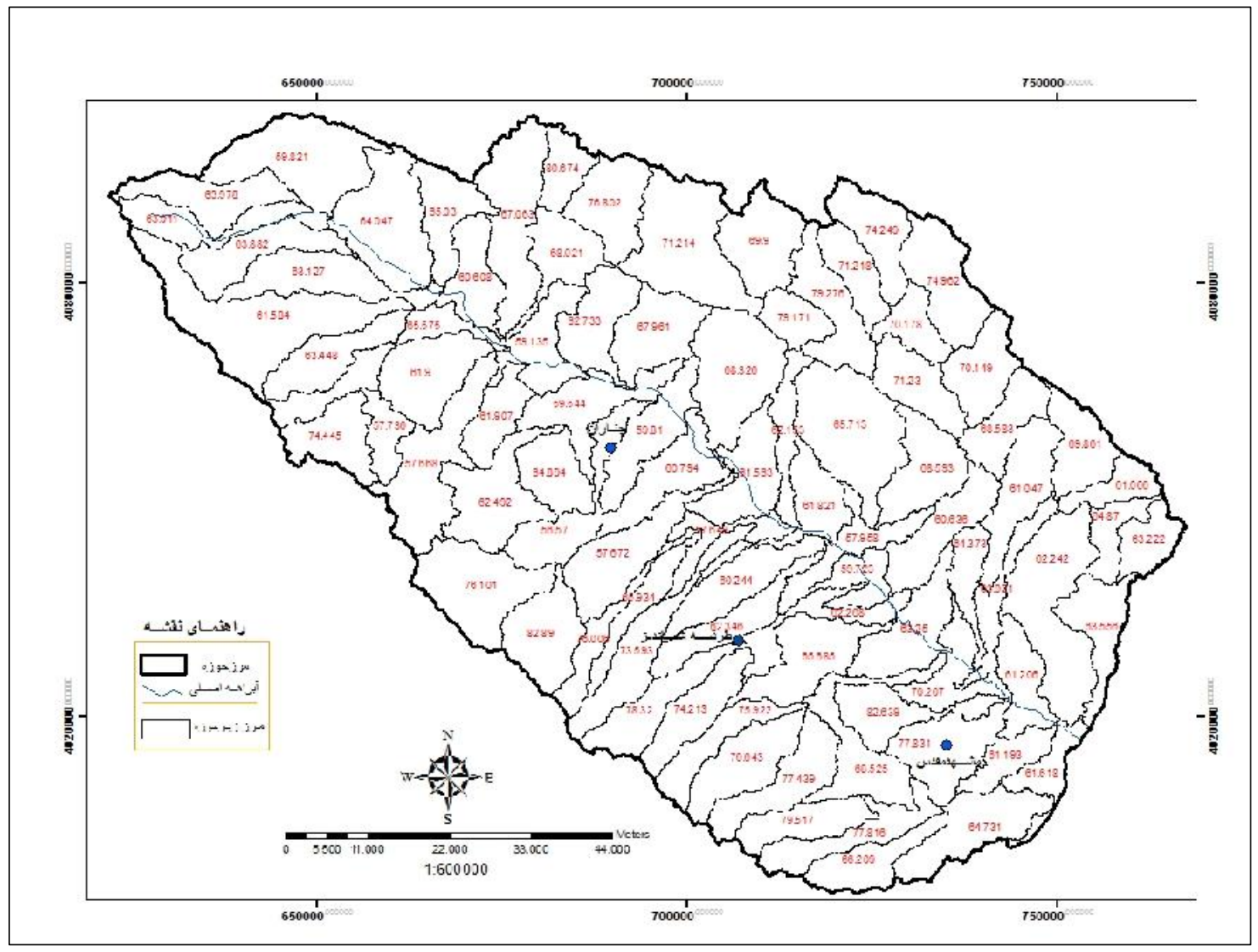

شكل V- نقشه شماره منحنى (CN) حوزه

Figure 7. Map of Curve Number $(\mathrm{CN})$ 


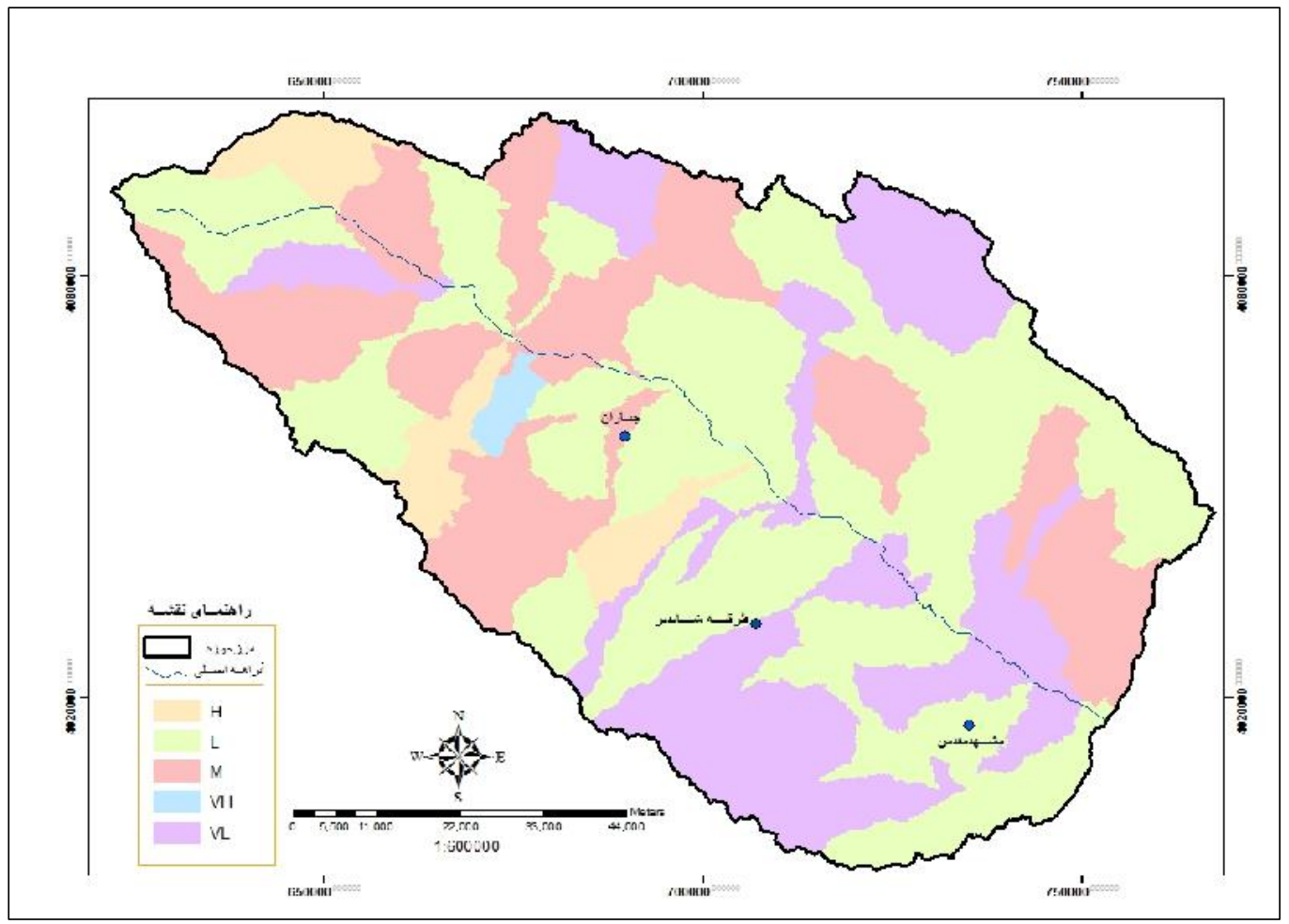

شكل ^- نقشه شدت يتانسيل سيلخيزى حوزه

Figure 8. Map of potential flooding discharge

داري/1/V.

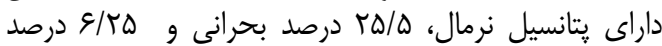
داراى تيتانسيل فوق بحرانى نواست

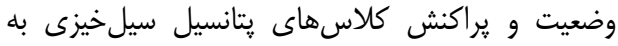
تفكيك شهرستانهاى حوزه نشان مى دهد كه شئ شهرست

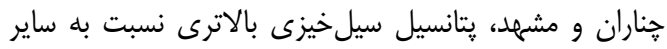

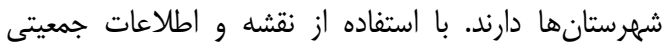

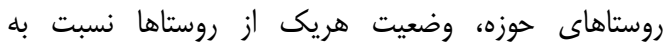

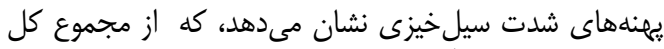

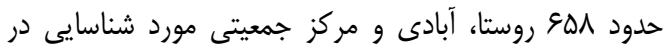

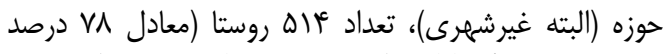

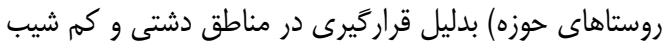

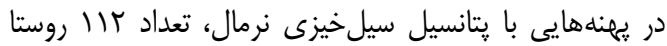

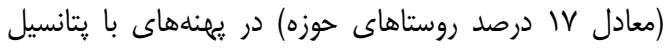

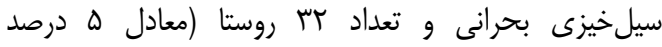

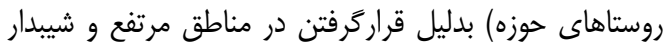

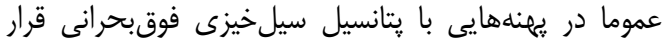

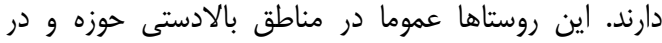
شهرستانهاى جناران و قوخان واقع شدان شانداند

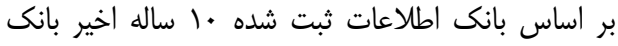

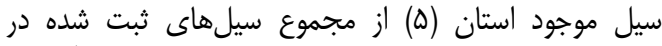

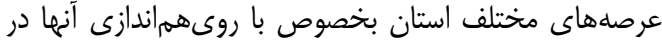
سطح حوزه بر روى نقشه يتانسيل سيل خيزى مشخص
در يك جمعبندى كلى، نتايج بدست آمده ازاين تحقيق رآ آندا

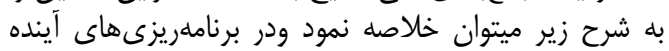

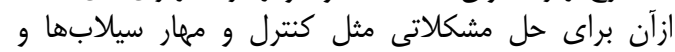

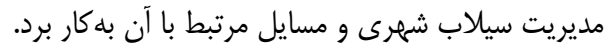

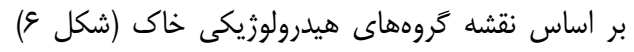

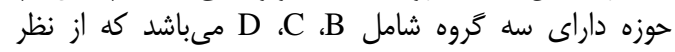

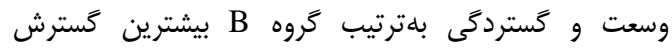

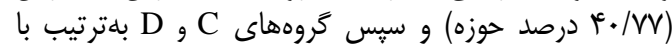

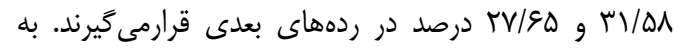

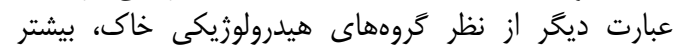

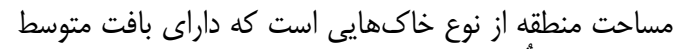

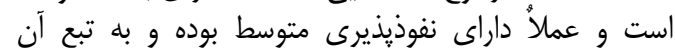
يتانسيل سيل خيزى متوسطى دارند.

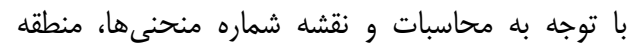

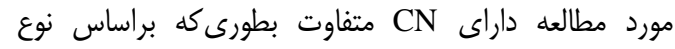

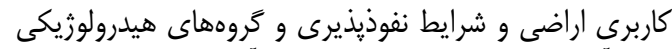

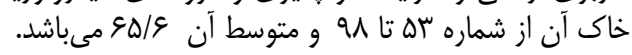

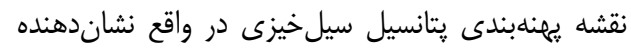

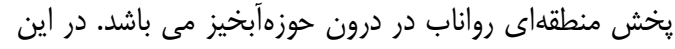

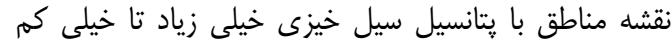

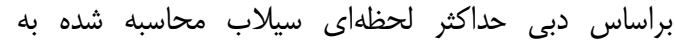

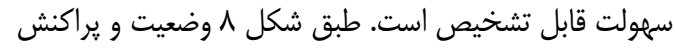

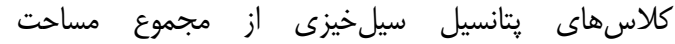


جهت اصلاح و احياء منابع آب و خا ك به مناطق باد آنا

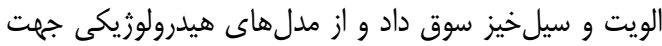

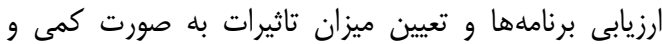
كيفى استفاده نمود.

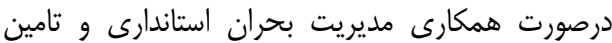

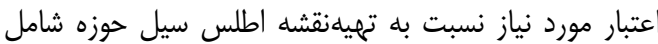

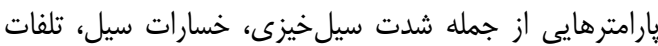

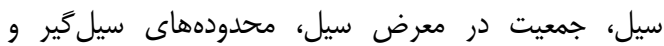

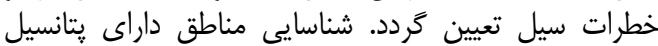

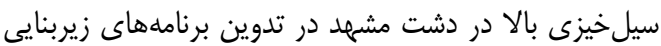

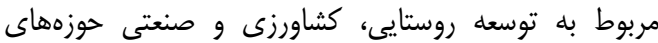

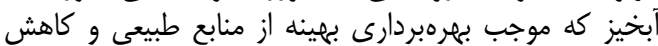

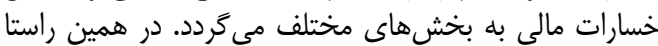

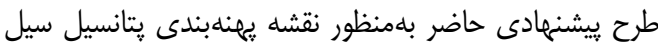

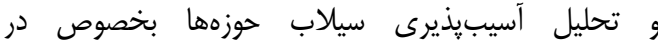

رودخانهاى واقع دردشت مشهل مى تواند كمك موثرى نمايد.

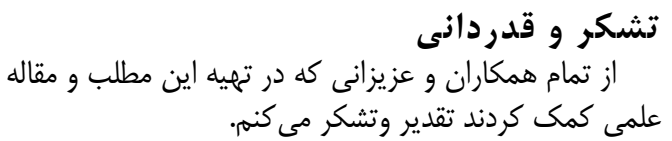

كه اكثر سيلابهاى ثبت شده (بيش از هاط درصد دهد) در

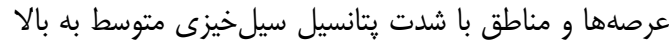
(بحرانى و فوق بحرانى) اتفاق افتادهاست.

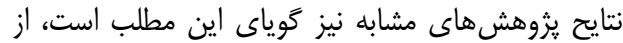

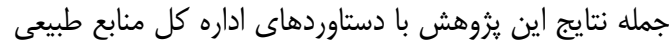

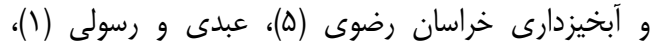

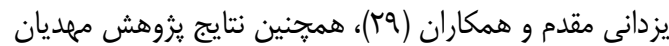

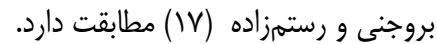

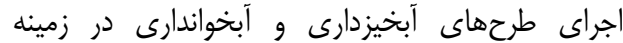

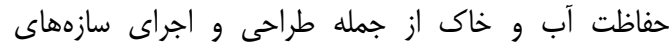
مهندسى مناسب از قبيل سدخاكى كوتاه و بندانحر افى و و وانى غيره

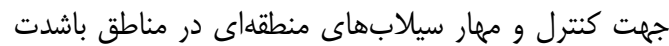

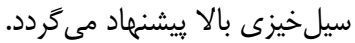

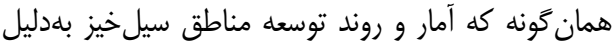

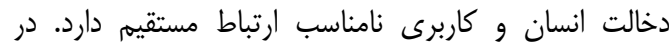

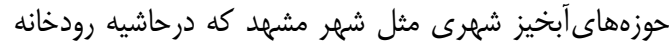

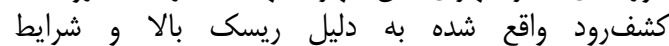

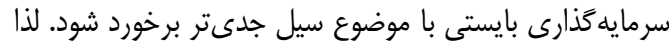

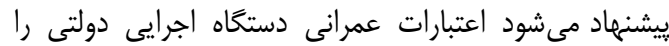

\section{منابع}

1. Abdi, P. and M. Rasuli. 2001. potential zonation flooding Zanjan Rood watershed using GIS, Proceeding of the Conference on Identification of Watershed Management Issues and Providing Appropriate Solutions in the Karoon and Zayandeh Rood Basin, Natural Resources and Animal Sciences Research Center.Char Mahal and Bakhtiari province (In Persian).

2. Alizadeh, A. 2006. Principles of Applied Hydrology. Imam Reza University Press. Thirty-fifth edition (In Persian).

3. Akbari, A. Abu Samah and F. Othman. 2009. Effect of Pixel Size on the Areal Storm Pattern Analysis using Kriging. Journal of Applied Sciences, 9: 3707-3714.

4. Akbari, A. Abu Samah and F. Othman. 2012. Integration of SRTM and TRMM date into the GISbased hydrological model for the purpose of flood modeling, Journal Hydrology and Earth System Sciences, 9: 1-29.

5. Department of Natural Resources and Watershed of Khorasan Razavi. 2013. Plan zoning map of potential flooding Razavi Khorasan (In Persian).

6. Ebrahimian, M. 2009. Application of Natural Resources Conservation Service - Curve Number Method for Runoff Estimation with GIS in the Kardeh Watershed, Iran European Journal of Scientific Research ISSN 1450-216X Vol.34 No.4: 575-590.

7. Ghaemi, E. and S. Morid. 1996. Modeling Flooding of Karkheh Sub-Watershed, Journal of Nivar. No. 30, Meteorological Organization of Iran, pp: 10-27 (In Persian).

8. Ghahraman, B. 2008. Short-term rain analysis in Khorasan, Journal of Iranian Watershed Science and Engineering, 2(4): 66-73 (In Persian).

9. Hamidi, N., M. Vafakhah and A. Najafi. 2016. Preparation of flood hazard risk maps in Nur watershed . the using of Analytic Hierarchy and fuzzy logic. Journal of Watershed Management Research, 7(14): 19-11 (In Persian).

10. Hawkins R. 2005. Runoff Curve Number Method: Examination of the Initial Abstraction Ratio. Proceedings of the Second Federal Interagency Hydrologic Modeling Conference, Las Vegas, Nevada.

11. Hosseinzadeh, M. 2011. Assessing the quality of ASTER DEMs for Hydrological Applications, International Conference on Environment Science and Engineering IPCBEE vol. IACSIT Press, Singapore (In Persian).

12. Huang, M., G. Jacques, W. Zhanli and Gt. Monique. 2006. A modification to the Soil Conservation Service curve number method for steep slopes in the Loess Plateau of China, Hydrological Process, 20: $579-589$.

13. Jalali, H. 2007. Investigating the Floods in Iran, Proceedings of the First Hydrological Conference of Iran, Faculty of Engineering, Tehran University, Ministry of Energy Publication (In Persian).

14. Khodayar, P. 2012. Checking the country's flood situation and problems. Proceedings. Web Site: //http://hydro.ir (In Persian).

15. Khosroshahi, M. 2008. Personal website with the title of flood related research background and flooding zones (Date of observation, 25/3/1391) http://khosromk.blogfa.com/post/120 (In Persian). 
16. Khosroshahi, M. 2001. Determining the role of watersheds in flood plain severity, PhD thesis, Natural Resources Department, Tarbiat Modarres University (In Persian).

17. Mahdian Borujeni, M. and E. Rostamzadeh. 2015. Evaluation of the Flood Potential of the Arctic Basin with GIS, Third Conference on Environmental, Energy and Biological Defense of Tehran (In Persian).

18. Mahdavi M. 2013. Applied Hydrology, Volume II, Tehran University Press. Eighth edition, 442 pp. (In Persian)

19. Monirul, M.D. and K. Islam. Sado. 2000. Development of flood hazard maps Bangladesh using NOAA-AVHRR images with GIS, Hydrological sciences-Journal, 45(3): 337-355.

20. Ministry of Energy. Regional Water Authority of Khorasan Razavi, Information about meteorological stations and hydrometers of the regional (In Persian).

21. Ministry of Energy. Iran Water Resources Management Organization. 2004. Water Resources Research Center (Tmab), Department of combination studies. Directions \& Conditions classification and coding watersheds and areas of study in the country, Publication No. 282 (In Persian).

22. Othman, F. and A. Akbari. 2011. Spatial rainfall analysis for an urbanized tropical river basin, International Journal of the Physical Sciences, 6(20): 4861-4868.

23. Qodsian, M. 1998. Flood Control and Drainage Engineering, (Translated) Tarbiat Modares University Press, Office of Science Publication, First Edition (In Persian).

24. Shabani, A., A. Imadi and R. Fazl. 2016. Investigating the Flood Potential and Determining the Flood Generation Areas (Case Study: Neka. Journal of Watershed.Management . Volume 7, Issue14, pp: 2028 (In Persian).

25. Stephan, R. 2002. Hydrologic investigation by the U.S Geological survey following the 1996 and 1997 floods in the Upper Yellostone River, Montana American Recourses Association. Annual Montana Section Meeting. Section one, pp: 1-18.

26. Tachikawa, T., M. Kaku and A. Iwasaki. 2009. ASTER GDEM validation. Presentation at the 35th ASTER Science Team Meeting, Kyoto, Japan.

27. Thavorntam, W., N. Wattanakij and C. Mongkolsawat. 2007. Estimation of rainfall spatial interpolation methods in North-East Thailand. Asian Conference on Remote Sensing (PWTC), Kuala Lumpur, Malaysia.

28. Webster, R. and M.A. Oliver. 2007. Geostatistics for Environmental Scientists. IN BARNETT, V. $2^{\text {nd }}$ Edition ed. UK, John Wiley \& Sons, Ltd.

29. Yazdani Moghadam, Y., R. Ghazavi, M. Khazaee and Z. Hezbavi. 2005. Investigation of flood capability in Kashan catchment using maximum flood discharge. The First National Conference on achievement method for constant development in agricultural parts.Iran (In Persian). 


\title{
Investigation Flooding Potential in The Kashafrud watershed, Mashhad The Method SCS and GIS
}

\author{
Mahmoud Azamirad ${ }^{1}$, Bijan ghahreman and Kazem Esmaili ${ }^{2}$
}

\author{
1 and 3- PhD Student and Associate Professor, of Water Sciences Engineering, Ferdowsi University of Mashhad \\ 2- Professor and Faculty of Agriculture, Department of Water Sciences Engineering, Ferdowsi University of \\ Mashhad,(Corresponding Author: Bijan_ghahreman@yahoo.com) \\ Received: January 10, $2017 \quad$ Accepted: November 29, 2017
}

\begin{abstract}
Kashafrud Watershed Area is the part of the Great Plains Gharehghom in the northeastern province of Khorasan Razavi with area of 8996 square kilometers and considered the main drain Mashhad plain. to determine flooding potential of Kashafrud watershed used of modified SCS Method, the GIS system according to classification of map watershed and Tamab grade 4 in the digital elevation model, mapping the distribution of precipitation, precipitation losses and land use. Meteorological data, including precipitation statistics and rainstorms (28 stations) related to the period received of the relevant organizations and reviewed. After calibration data based on a common time base for 25 years (1989-1988 to2013-2012) and remove of suspicious data, in some cases rebuild the lengthening period. Layers of information is used such as maps: weather stations location, topography, land use, soil, vegetation, Political divisions of province and divisions watershed of Tamab. receiving DEM and making any necessary modifications basin boundary and physiographic characteristics calculated such as area, perimeter, height, slope, time of concentration. value of $\mathrm{CN}$ calculated by using the land use map and soil hydrology groups performed. Analysis Storm determined by using the software SMADA and standard distribution function (Pearson type 3 ) and value of of rainfall and storm return periods of 2 to 100 years. After calculation of weighted average height of the runoff in each subwatershed (sub 86), to determine the flood zones watershed, estimates maximum flooding (Qmax) caused by rainfall effective and drawn flooding potential map of watershed. Of the total area of watershed is, $68.25 \%$ of the normal flooding potential, $25.5 \%$ of of critical and is $6.25 \%$.supercritical flooding potential. Cities Chenaran and Mashhad are flooding potential than other cities. From a total of 658 villages and population center recognized in watershed, $78 \%$ of the villages due to their placement in plain areas and low-slope are in the zone of potential flooding normal, $17 \%$ of the villages in the area with the potential flooding of critical and $5 \%$ of the villages due to the inclusion in the Highlands and steep with the potential flooding zone supercritical.
\end{abstract}

Keywords: Flooding potential, Watershed Area,Flood, Kashafrud watershed, Method SCS 